CRÍTICA, Revista Hispanoamericana de Filosofia

Vol. XXVII, No. 81 (diciembre 1995): 55-78

\title{
CHISHOLMIAN FOUNDATIONALISM AND THE NATURALIZATION OF EPISTEMOLOGY*
}

Jane Duran

University of California at Santa Barbara

Repeated and consistent attacks on foundationalism - both the narrower, professionally epistemological variety, and the greater search for "foundations" as a whole- seem to have little effect on its recurring and episodic popularity. ${ }^{1}$

The rubric "foundationalism" now seems a trifle outdated, even qua theory of epistemic justification, for recent literature has tended to mention reliabilism and to allude to some extent to the project of naturalizing epistemology. ${ }^{2}$ Audi has mentioned that "it is at least very natural for a reliabilist to be a modest foundationalist", and it will be part of the argument of this paper that it is importantly

* Work on this paper was completed in part with the assistance of the Department of Education, grant DOE G0083-03651.

1 The fact that some authors now maintain coherentism to hold the upper hand among theories of epistemic justification seems to have little to do with the number of citations to foundationalism in the literature. To cite a few recent examples, "Chisholm and Coherence", by Richard Foley, in Philosophical Studies, 38, pp. 53-63; "Chisholm's Foundationalism, by Timm Triplett, in Philosophical Studies, 38, pp. 141-153; "Some Remarks on Chisholm's Epistemology", in Noûs, 14, pp. 565-586.

2 The two recent large works on the naturalization project are Alvin Goldman's Epistemology and Cognitive Science, Cambridge, MA: Harvard University Press, 1986, and Hilary Kornblith's Naturalizing Epistemology, Cambridge, MA: Bradford of MIT Press, 1985. 
insightful to mention reliabilism and foundationalism in the same breath, so to speak, however much it might seem to go against the grain in other ways. ${ }^{3}$ In a recent piece I have argued that reliabilism and foundationalism suffer from some of the same defects, ${ }^{4}$ and here I want to return to foundationalism and examine it in greater detail, particularly given the recent trends toward theories which are more sophisticated from the standpoint of cognitive science, or which make at least passing reference to the manner in which epistemic agents actually function. If the newer, reliabilist theories lend themselves to criticism from the standpoint of their relationship to foundationalism, as I have argued, might it not be plausible to think that foundationalism itself is vulnerable to the sorts of attacks which have been made against these theories?

Chisholm's foundationalism has frequently been taken as paradigmatic, at least partly because of its clear formulation. Alston has referred to it as "classical" in its foundationalist structure; it is frequently cited in the large literature on foundationalism. ${ }^{5}$ In the following sections I propose to set out clearly some of the leading features of Chisholm's foundationalism as formulated in the second edition of Theory of Knowledge (1977), and then subject it to two lines of criticism. The first line will ask us to see whether this theory is vulnerable to the paradigmatic objections lodged against foundationalism, many of which were formulated tidily by Austin in Sense and Sensibil-

3 The original Audi piece is "Foundationalism, Epistemic Dependence and Defeasibility", in Synthèse, vol. 55, no. 1, pp. 134-135.

4 See my "Reliabilism, Foundationalism and Naturalized Epistemic Justification Theory", in Metaphilosophy, vol. 19, no. 2.

5 See William P. Alston, "Some Remarks on Chisholm's Epistemology", in Noûs, vol. 14, pp. 565-586, passim. 
$i^{6}{ }^{6}$ Part of the focus here will be on why the theory is vulnerable, rather than the mere fact of its vulnerability, which should not be too surprising. The second line will reiterate the reasons for the theory's vulnerability and relate them to foundationalism's resemblance to reliabilism. The larger strategy of our argument will be to show that both sorts of theories tend to be susceptible to lines of argument which run contra privileged access, and for the same sorts of reasons; that we can draw some valuable conclusions from this with regard to epistemic justification theory and epistemology as a whole; and that the conclusions which we draw point us in the way of still another sort of project which is more descriptively accurate than either theory, more sensitive to aspects of cognition than either theory, and which is the current leading candidate for development into a viable naturalized theory of epistemic justification.

\section{I}

An interesting feature of Theory of Knowledge is that it assumes from the start that the reader's intuitions regarding the process of epistemic justification are foundationalist. These intuitions, as formulated by Chisholm, are themselves exemplary and hence pertinent to our purposes:

It should also be noted that when we ask ourselves, concerning what we may think we know to be true, 'What justification do I have for believing this?'...

In many instances the answers to our questions [of what justifies a claim or belief] will take the following form:

What justifies me in counting it as evident (in thinking that I know) that $a$ is $F$ is the fact that it is evident to me that $b$ is $G$... Such an answer therefore presupposes an

${ }^{6}$ J.L. Austin, Sense and Sensibilia, Oxford: Oxford University Press, 1967. 
epistemic principle, what we might call a 'rule of evidence'. The rule would have the form:

If it is evident to me that $b$ is $g$, then it is evident to me that $a$ is $F$ ?

Here Chisholm tries to make evident our intuitions, but the view espoused is, of course, not unrelated to the rest of Chisholm's view. His foundationalist stopping place is the directly evident. ${ }^{8}$ At some point, it is no longer necessary to seek justification for any given claim. ${ }^{9}$

We may think of the directly evident as resting upon what is self-presenting, in Chisholm's terminology, and what is self-presenting amounts to what other philosophers have labeled self-justified. ${ }^{10}$

What one wants to say at this point, and which comes as no surprise, is that the self-presenting, as formulated by Chisholm, is directly related to the notion of privileged access. My knowledge that I am thinking stems from the nature of thinking itself — as Chisholm says, "it would be impossible for $\mathrm{S}$ to be thinking unless it would be evident to $S$ that he was thinking". It is also a sort of knowledge which no one else can possess; others may claim (perhaps truly, excluding the brain-in-the-vat hypothesis) to know

7 Roderick Chisholm, Theory of Knowledge, Englewood Cliffs, NJ: Prentice-Hall, 1977, pp. 18-19.

${ }^{8}$ Ibid., pp. 19-20. For a fine commentary on this notion and its relationship to other aspects of Chisholm's view, see Triplett, in op. cit., above.

9 What Chisholm actually says is "What justifies me in thinking that $\mathrm{I}$ now know that $a$ is $F$ is simply the fact that $a$ is $F$ ". (Ibid.)

10 The self-presenting is glossed as "a state of affairs for $S$, such that, if it occurs, then it is evident to $S$. Hence we could say that the Cartesian statement 'I am thinking' expresses what is self-presenting for $S$-provided he is thinking. For it would be impossible for $S$ to be thinking unless it would be evident to $S$ that he was thinking", pp. 23-24, op. cit. 
that I am thinking, but no one has the sort of evidence about my thinking that I have, save me. Any evidence that third parties would possess would be behavioral, unless they had access to brain states (and even this is suspect). And, traditionally, one has wanted to deem this first-person evidence the best sort of evidence. The mirror metaphor, to which the literature frequently alludes, reminds us that the mirror can be no more perfectly polished than in the situation where one does not have to go outside oneself to obtain either the cognitive experience or the reflection of the cognitive experience.

Although Chisholm is careful not to employ the term "incorrigible" (thus making his views an advance over the older views, some of which were indubitably tied to positivism, and many of which tried to anchor themselves to "incorrigibility"), ${ }^{11}$ it is important to try to clarify the relationship between the self-presenting, self-justification and incorrigibility, for as I will argue, these notions are related in a very important way.

To continue with our delineation of the self-presenting and privileged access, may one be wrong about "it being evident to [one] that [one] was thinking"? May one be wrong about how one is "appeared to", or about how things appear to one, to introduce another favorite of privileged access? Chisholm has created a number of distinctions between the sorts of statements that generally fall into the privileged access category. To paraphrase briefly, some of these statements - according to Chisholm (and here we do refer to the larger theory) - are nothing more than belief statements, and others ("It seems to me...") are statements which provide a kind of hedge, but which fail to describe

11 For an interesting appraisal of the relationship between epistemic incorrigibility and logical positivism (the "Received View"), see The Structure of Scientific Theories, en Frederick Suppe (comp.), University of Illinois Press, Champaign-Urbana, IL: 1977, esp. pp. 619-633. 
the directly evident. The statement "This appears white to me" is, however, according to Chisholm, a statement which is self-presenting. As we have indicated, one would like to gloss this as self-justified. Here is Chisholm one more time:

To the question 'What justification do I have for thinking that I know or for counting it as evident that something now looks red to me or tastes sour?' I could reply only by reiterating that something now does look red or taste sour. ${ }^{12}$

Chisholm modifies the syntactic structure of these sentences with his locutions "appeared to redly" or "sensed sourly". Now his self-justifying locutions may not be vulnerable to arguments against incorrigibility, or to incorrigibility counterexamples, since incorrigibility was never claimed for them. ${ }^{13}$ The difficulty, however, is that selfjustification, qua epistemic notion, is sufficiently strong and rigid so that a number of difficulties raised against incorrigibility will also be difficulties for the self-presenting or self-justifying statement. None of the foregoing implies that foundationalist views cannot begin from, for example, a deductively valid foundation. But that sort of foundationalism has little to do with the acquisition of empiricallybased knowledge, which is the point of Chisholm's work.

Let us, at this point, examine a classic line contra incorrigibility and see whether or not the line is also damaging to a view like Chisholm's which seizes as a foundation the stopping place of the self-justified. If, as I am about to argue, many of the criticisms raised against incorrigibility also go through against self-justification, there will be good reason

12 Chisholm, op. cit., p. 29.

13 One thinks, for example, of the rather elaborate counterexamples to incorrigibility which Lehrer has concocted in "Why Not Skepticism?", Philosophical Forum, vol. II, no. 3, Spring 1971. 
to believe that most (if not all) foundationalisms are shaky, insofar as they rest on a structure related to notions of privileged access. ${ }^{14}$ The literature bears out this contention, in that even the so-called "modest foundationalism" bears the putative relationship, as do foundationalisms which are less than modest. In any case, at a later point in our argument we will tie these notions in with the newer, more cognitively-oriented lines of epistemic endeavor.

The original Austin passage reads as follows:

Again, if I had said only, 'That looks like a star', I could have faced with comparative equanimity the revelation that it isn't a star, and so on. Reflections of this kind apparently give rise to the idea that there is or could be a kind of sentence in the utterance of which I take no chances at all, my commitment is absolutely minimal; so that in principle nothing could show that I had made a mistake, and my remark would be 'incorrigible'.

But in fact this ideal goal is completely unattainable... I may say 'Magenta' wrongly either by a mere slip, having meant to say 'Vermilion'; or because I don't know quite what 'magenta' means, what shade of colour is called magenta; or again, because I was unable to, or perhaps just didn't, really notice or attend to or properly size up the colour before me. Thus, there is always the possibility not only that I may be brought to admit 'magenta' wasn't the right word to pick on for the colour before me, but also that I may be brought to see, or perhaps remember, that the colour before me just wasn't magenta. And this holds for the case in which I say, 'It seems to me personally here and now, as if I were seeing

14 I have argued in another place that even the so-called "modest foundationalisms" ( $c f r$. Pastin, "Modest Foundationalism and SelfWarrant", in Essays on Knowledge and Justification, George S. Pappas and Marshall Swain, eds., Ithaca, NY: Cornell University Press, 1978), falter at the same place and are, in general, no more successful than the more radical or rigid versions of foundationalism. See my "Reliabilism, Foundationalism and Naturalized Epistemic Justification Theory", in Metaphilosophy, vol. 19, no. 2. 
something magenta', just as much as for the case in which I say 'That is magenta'. The first formula may be more cautious, but it isn't incorrigible. ${ }^{15}$

To be sure, Austin is most concerned with the notion that a certain type of proposition may be incorrigible; it is in fact his claim that incorrigibility has more to do with circumstance than with types of propositions. ${ }^{16}$ But what we are concerned with here is whether or not the Austinian objections may be applied to Chisholm. Chisholm refers to a "class of directly evident... statements". He is explicit about their being "appear' — and 'seem' - statements". Austin is obviously talking about a class of sentences or statements; he says "Reflections of this kind apparently give rise to the idea that there is or could be a kind of sentence..." Apparently Austin and Chisholm have the same sorts of sentences in mind. Contra incorrigibility, Austin finds ways in which one could have been mistaken in such an utterance. Interestingly enough, the evidence that would be adduced goes beyond the notion of the selfpresenting. Hence, by modus tollens, if I am able to deny the antecedent because I can deny the consequent, then the antecedent had the consequent as a necessary condition. In other words, if my uttering "It seems to me personally, here and now, as if I were seeing something magenta", is glossed as incorrigible, then (following Austin), that would imply that it is not the case that I meant to say 'Vermilion'. (Interestingly enough, Dretske has an analogous argument regarding skepticism and the presuppositional consequent. $)^{17}$ But if later it can be shown that it is the case that I meant

15 J.L. Austin, in op.cit., pp. 112-113.

16 Ibid., pp. 114-115.

17 Fred Dretske, "Epistemic Operators", in Journal of Philosophy, LXVII, December 1971. 
to say 'Vermilion', then clearly there were necessary conditions for the original statement's being incorrigible which were not, perhaps, fully taken into account at the time.

Now that this modus tollens sort of argument works against incorrigibility is, I think, clear. In any case, Austin's argument (and similar sorts of arguments made by others $)^{18}$ are frequently cited as strong objections to classical foundationalism resting on a bedrock of incorrigibility. But suppose one claims that such a statement ("It seems to me personally, here and now, as if I were seeing something magenta") was merely self-presenting, or as I have glossed it, self-justifying. The claim, it will be recalled, is that "I could reply only by reiterating that it now does look red or taste sour". 19 We have assessed this claim as being somewhat weaker than incorrigibility. But notice the implicit structure of the claim. The iterative status is intended to remind us that this self-presenting statement stands alone epistemically, that is, that it does not require any other statement by way of justification. But the statement is, of course, a statement of privileged access. Without third person access to brain states, of the type that sometimes is adverted to in "philosophers" wonderland" counterexamples, no one could know how something looks to me because how something looks to me is completely an interior phenomenon. Now in this case, as in Austin's original example where incorrigibility was being examined, it is not implausible to think that a person might later be brought to modify or change the claim. So far, this might be deemed to be not particularly deleterious to Chisholm's project, since he did not use the term "incorrigible". But it is also at least plausible to think that the modification of such a statement casts some doubt on whether or not the statement ever was

18 See fn. 13.

19 Chisholm, loc. cit. 
self-presenting (or self-justifying) in the first place. For if we think of the iterative condition ("I could reply only...") as being a necessary condition for the statement's being self-presenting ("... reply only..."), then something has clearly gone wrong. Getting one to admit that one might have meant to say "Vermilion" (to trot Austin out again) seems to have the implication that it was a necessary condition for the statement's being self-presenting that one had not initially meant to say "Vermilion". Clearly, one could initially have replied to the query "What justification do you have...?" by something other than only "it looks..." (or in the case of the gustatory) "... it tastes".

The argument here is not as forceful as it is in the case of incorrigibility, and I take this to be precisely because our intuitions about what actually constitutes "selfjustification" are shaky. But clearly Chisholm's phrase "I could reply only..." is too strong, and something has gone awry. What one is tempted to say is that similar arguments can be made against most of the extant versions of foundationalism, and for the evident reason that the statements upon which foundationalisms tend to rest are largely statements of privileged access. As I have argued in another piece, this is true even for foundationalisms, like Pastin's, which claim to have solved the problems of the more classical foundationalisms. Statements of privileged access do intuitively strike one as having a peculiar epistemic status. But the difficulty is in making the extraordinary leap required to move from the plausible notion that such statements might be error-prone less frequently than statements not of privileged access to the very implausible notion that such statements are never, or almost never, refutable, or that they may be thought of as providing their own justification, by iteration, in each and every case.

Our argument thus far has been that Chisholm's foundationalism is vulnerable because it relies on notions of 
privileged access which are susceptible, in at least some way, to the well-known counterarguments formulated by Austin and others. In a tightly-argued recent journal piece, Triplett has argued that Chisholm's theory is guilty of having no coherent account of precisely how the "directly evident" (statements of the sort we have been examining) actually does confer evidence upon the rest of the pyramid, the "indirectly evident" ${ }^{20}$ I cannot recapitulate Triplett's argument here, but it appears to be another telling blow against the possibility of constructing such a foundationalism.

\section{II}

We have alluded to the relationship between foundationalism and reliabilism at an earlier point in this paper. The recent work on the naturalization of epistemology has tended to center around work that is either termed "reliabilist" or that has at least some reference to cognitive processes. ${ }^{21}$ But reliabilism, however contemporary its appeal, bears at least some recognizable relationship to foundationalism itself. As Audi has remarked, one might be tempted to think of reliabilism as a sort of weakened foundationalism. The reasons for this are not arcane.

20 Tim Triplett, "Chisholm's Foundationalism”, in Philosophical Studies, 38, 1980, pp. 141-153. Triplett's account of difficulties and incoherencies in Chisholm's epistemic logic is excellent, as are two other journal pieces critical of the Chisholmian system: Richard Foley, "Chisholm and Coherence", in Philosophical Studies, 38, 1980, pp. 53-63, and William P. Alston, "Some Remarks on Chisholm's Epistemology", in Noûs, 14, 1980, pp. 565-586. In the main, however, their criticisms are more finely and specifically tuned than the criticisms broached in this article. Alston does, however, refer to certain peculiarities and difficulties with the Chisholmian use of privileged access.

21 See fn. 2. 
As I have indicated in another piece, ${ }^{22}$ most reliabilist theories are somewhat vague about the constitutive elements of whatever "reliable cognitive process" they purport to adduce. Although I will not repeat the full weight of such arguments here, it is clear that the paradigm of a reliable cognitive process in the literature is frequently a visual process - certainly, it is often a sensory process. ${ }^{23}$ But the sorts of statements which result from such processes tend, particularly if they are given a peculiar epistemic status, to be either statements of privileged access or (perhaps more importantly) statements which when carefully examined themselves rely on statements of privileged access. Hence, tersely, reliabilist theories are frequently subject to the sorts of objections we have already cited.

Clearly, however, this need not necessarily be the case. The "reliable cognitive process" to which the theorist refers, implicitly or explicitly, need not be a sensory process. Perhaps a memory process or some other process could be cited. But my criticism has been that many of the theories do not, in fact, spell out the cognitive process in sufficiently clear detail to make it theoretically formulable, save in the most rough-and-ready fashion. Now reliabilism, to be sure, constitutes only one sort of naturalized epistemic theory. But if one of the virtues of naturalization is supposed to be that it saves us from the conundrums of normative epistemology, while providing us an account of epistemics which is actually instantiable in a living agent, ${ }^{24}$ then reliabilist

22 See fn. 3.

23 Heil, for example, takes a perceptual process as paradigmatic in "Reliability and Epistemic Merit", Australasian Journal of Philosophy, vol. 62, no. 4, p. 327.

24 On the presumption that an epistemic "ought" implies an epistemic "can", see my "Descriptive Epistemology", in Metaphilosophy, vol. 15, nos. $3 \& 4,1984$. On the difficulties of inconsistency and the hypernormative character of the standard non-naturalized epistemic 
theory, qua naturalized epistemic theory, is a case of the emperor's new clothes. Closely examined, the theories offer us nothing.

The argument thus far, I maintain, leads us to the following point. Foundationalisms tend to be vulnerable (Chisholm's being taken as paradigmatic) because of their reliance on privileged access. Reliabilism, as an exemplar of naturalization, tends to have the same difficulties; to be just, one wants to interject the caveat that many of the cognitive processes alluded to by such theories are so poorly spelled out that it is not immediately clear whether the theory implicitly alludes to privileged access or not. In any case, if one buys the notion that an epistemic "ought" implies an epistemic "can", another difficulty for foundationalism is clearly that it is apsychologistic and has - regardless of its other defects - very little to do with the way in which epistemic agents actually function. ${ }^{25} \mathrm{An}$ important reason for wanting to accept the notion that our epistemic "oughts" should be instantiable is that, if they are not, the very normative nature of classical epistemology is subverted. The naturalization of epistemology is supposed to save us from this very difficulty. But then if we may conclude that (saving the causal theories, which may be deemed to be only weakly naturalized) the chief exemplar of a naturalized theory, viz. reliabilism, suffers from some of the same defects as foundationalism itself, it is clear that what is needed is a different sort of naturalized theory. Fortunately, certain work in cognitive science, particularly when applied to the perhaps more intuitive coherence theories, seems to show us the way out.

justification theories, see my "A Contextualist Modification of Cornman", in Philosophia, vol. 16, nos. 2 \& 3, 1986.

25 Kornblith first made this point in "Beyond Foundationalism and the Coherence Theory", in Journal of Philosophy, October 1980. 
Coherentism has the intuitive appeal that our beliefs seem to come in clusters. Repeated metaphors of clusters, webs and networks remind us that the shaking or rendering dubitable of one belief seems to have a profound effect on many others, but not necessarily in the pyramidal or chainlike fashion that foundationalists might have us describe. ${ }^{26}$ If the upshot of the argument of the two preceding sections is that we do indeed need a more naturalized theory of epistemic justification (bearing in mind that a strong argument for the necessity of such a theory is the line that "ought" implies "can", meaning that what we recommend for our epistemic agents they should be able to perform), and that both reliabilism and foundationalism seem to suffer from a reliance on privileged access - foundationalism, admittedly, not being naturalized in the first place - a naturalized version of a coherence theory might seem to be the best candidate for the naturalization of epistemic justification theory. Aside from possessing the appeal that our beliefs seem to come in groups, coherentism also seems closer to the structure of many extant cognitive theories, with their emphasis on nets and connections. ${ }^{27}$ One could, of course, think of some amalgam of foundationalist and coherentist views for a naturalized theory, but the simpler and more elegant point of departure seems to be to think in terms of coherentism simpliciter, since it already possesses the virtue of being a clearly demarcated theory.

Now in previous pieces I have argued that contemporary work in cognitive science can aid us in the formulation of such a theory, and I have provided a sketch of the

26 Even a work like Quine's "Two Dogmas" seems to employ such a metaphor.

27 See fn. 24. 
rudiments of such a theory. ${ }^{28}$ I will not recapitulate all the arguments here. Suffice it to say that it appears that a naturalized version of a coherence theory not only meets the "ought"-"can" desideratum, but saves coherentism, at least on the first analysis, from some of the problems which have plagued it over the course of time.

As I have argued, an important group of considerations against coherentism as it is usually formulated is contained in the widely-cited Cornman piece, "Foundational versus Nonfoundational Theories of Empirical Justification". ${ }^{29}$ Briefly, Cornman is concerned about the problems of consistency, size, scope and rigor within a cohering justificatory set. More technically, Cornman is concerned that for any two competing explanatory sets, $x$ and $y$, there will be no non-arbitrary way to try to decide between the two sets, since it is not clear what could be counted as giving a set greater explanatory (and hence justificatory) power. ${ }^{30}$ In addition, Cornman is concerned that any set which purports to provide maximal justificatory power will also be inconsistent. ${ }^{31}$ It might, for example contain inconsistent elements of explanation derived from competing theories in physics, and so forth. I have argued that Cornman finds no non-arbitrary way to decide between competing sets because Cornman thinks only of the problem of a coherence theory formulated within the standard normative tradition - a tradition which tries to satisfy the demands of a Pyrrhonian skeptic, which is apsychologistic and acon-

28 See my "Reliabilism, Foundationalism and Naturalized Epistemic Justification Theory", in Metaphilosophy, vol. 19, no. 2.

29 James W. Cornman, "Foundational versus Nonfoundational Theories of Empirical Justification", in Pappas and Swain, op. cit.

30 Ibid., p. 242.

31 Ibid. 
textual in its modeling, and which has virtually nothing to do with the actual functioning of an epistemic agent. ${ }^{32}$

Cursorily, my model asks us to think of a justificatory set, at least initially, as composed of whatever utterances an agent might make in reply to queries from a skeptical challenger, queries which are understood by the agent as intended to produce doubt. My model requires that we recognize that the cognitive processing of most agents is limited, and that constraints on both short-term and longterm memory make it unlikely that an agent will produce anything resembling the sort of set about which Cornman is concerned, unless the agent has special training or unless the context of the situation deems such a set appropriate. The fact that, on a naturalized view, the justificatory set would be much smaller does not, of course, mean that every such set would be saved from problems of consistency or size. In fact, some naturalized sets may have a greater propensity to inconsistency, at least on a superficial level. But the sheer delimitability of such a set means that the theoretical conundra propounded by Cornman are unlikely to occur in the way typically ascribed to classical coherentism.

Now two recent important works by professional epistemologists lend credence to my overall contention that what epistemic justification theory requires is some sort of naturalization. Goldman's Epistemology and Cognition, and Kornblith's anthology Naturalizing Epistemology, both support this contention. ${ }^{33}$ Kornblith's work, as a collection of essays, cannot of course take a united stand, and Goldman's work is concerned to use cognitive science to help formulate a normative theory of justification in the mainline tradition. (That is to say that Goldman is con-

32 See my "A Contextualist Modification of Cornman", in op. cit.

33 See fn. 2. 
cerned to use naturalized principles and theoretical work as a basis for formulating, among other things, a theory of justification which replies to the concerns of the skeptic, might be sufficient to respond to the Gettier examples, and so forth.) My own aim is simply to provide a more descriptively-adequate account of the process of epistemic justification, and hence my goal is a somewhat less mammoth one than Goldman's. Nevertheless, it might prove instructive to see what insights can be gleaned from these two works which might aid us in our project.

Goldman's work contains two chapters which are particularly helpful, "Skepticism" and "Perception". I have argued that the sorts of coherentist problems with which Cornman, for example, is concerned have to do with seeing a coherence theory as (like foundationalism) a device for responding to the skeptic. Goldman remarks, a bit revolutionarily, that "the nature of knowledge and the nature of justification are matters of independent interest, quite apart from the tenability of skepticism. Thus, while I remain mindful of skepticism in these discussions, it does not wholly dominate them. Skepticism is only one concern of epistemology; its significance should not be blown out of proportion." 34 And:

Now let us assume that global skepticism wins the day. Would that spell the end of epistemology? Not necessarily. Even if there are not any sufficiently reliable cognitive processes to qualify a person for either knowledge or justified belief, there might still be differences among processes in degrees of reliability.... Even if epistemic honors like knowledge or justified belief are beyond our grasp, that does not mean that all distinctions should be abandoned. ${ }^{35}$

34 Goldman, op. cit., p. 39.

35 Ibid., p. 40. 
And, finally, Goldman reminds us, although his system is neutral with regard to the foundationalist-coherentist debate, "the foundationalist-coherentist controversy depends for its resolution on psychological facts... Once a clear choice of terminology is made,..., psychological facts have an important bearing. Certainly this is so if perceptual beliefs are one candidate class of basic beliefs. The viability of their candidacy for justificational 'basicness' depends on the processes that generate such beliefs. This is a matter to be settled by the psychology of perception". ${ }^{36}$ Kornblith also adheres to this view, noting that there is room for disagreement about what is constitutive of justification. ${ }^{37}$

Now if, as I have contended, the agent's justificatory set is (seen descriptively) composed of a set of utterances produced in response to a skeptical inquiry, and if, as Goldman, Kornblith and others want to contend, we can learn something useful for epistemology by examining psychology and the cognitive sciences generally, then I think we can be more precise about the justificatory set. ${ }^{38}$ The set is produced through recognition of intent of the challenger; indeed, the entire production of the set may be thought of as an intentional process. ${ }^{39}$ The social process of epistemic justification - that is, the process of justification seen descriptively, psychologistically, and with agent acting in context - is one of speech acts (constrained by STM and

36 Ibid., p. 195.

37 What Kornblith actually says is "The standard account of what it is to be justified in believing a proposition is an apsychological account." Kornblith, "Beyond Foundationalism and the Coherence Theory", reprinted in Kornblith, op. cit., p. 117.

38 I have been more precise about the set in other pieces. See my "Cornman", in op. cit., and my "Reliabilism", in op. cit.

39 The focus on intentionality required to come to grips with the set is examined specifically in my "Intentionality and Epistemology", in The Monist, vol. 69, no. 4. 
LTM) and responses to speech acts; the skeptical challenger is either convinced by the reasons adduced as justifiers or is not. Taking note of these sorts of facts is particularly helpful in allowing one to be specific about the size of the justificatory set while at the same time limiting its size, thus making it unlikely to produce the sorts of difficulties Cornman finds so pronounced.

More precisely still, norms and practices, along with cognitive constraints when the mind/brain is seen on the computational model, ${ }^{40}$ determine the verbal output of the agent which thus determines the set. The set reduces to that which may be specified by the collection of putative justifiers, each justificatory utterance resulting from a process characterized by the agent's recognition of skeptical challenge and the agent's attempt to answer it. Final curtailment or limiting of the set comes about when the challenger recognizes the force of the justifiers and acquiesces or terminates the process of skeptical challenge.

It might very well be objected that the idiosyncratic nature of the production of such sets militates against a theoretical overview of said production and its components counting as epistemological in any interesting sense. But to say so much is to beg the question: such an avowal rests, again, on the strength which the normative tradition possesses as a force against which other theorizing is measured, and further more fails to take into consideration much recent work in logical operations and speech acts which supports the notion that these theoretical constructs are indeed importantly epistemological in their ramifications. When Scribner and Cole recount the tendency of Uzbekistanis to reason only within the framework of what

40 Pylyshyn's account of the computational model is particularly well done. See Computation and Cognition, Zenon W. Pylyshyn, Cambridge, MA: Bradford of MIT Press, 1984. 
they have already acquired through the senses (thus making it very difficult for them to reason in the form which educated Westerners think of as syllogistic, at least when such material is completely hypothetical) they are telling us something which is important not only for social science research but for naturalized epistemology. To assert that this sort of material is epistemically irrelevant is to value only theories which are largely or entirely non-instantiable, as Kornblith asserts.

In this section I have argued that close scrutiny of foundationalism (especially Chisholm's) reveals that those who criticized reliabilism and foundationalism in the same breath were quite right, so to speak, and that epistemic justification theory needs to be naturalized in a way which genuinely goes through. My contention has been that coherentism, modified through the process of naturalization, is a likely candidate for such a theory, and that allusion to the cognitive sciences (an advertence which has repeatedly been mentioned in the literature) not only provides a way out but simultaneously seems to provide a partial answer to the critics who had denounced coherentism initially. My contention has been that a descriptively-oriented model of the justificatory set should be the basis or starting point for any theory of justification, and that a naturalized version of such a set is readily attainable. Although I have not dwelt on the possibility of normativizing such a set (making it strong enough epistemically to grapple with the Gettier examples and other traditional skeptical concerns), I contend that it is possible to normativize such a set, a possibility to which I have alluded in other work. ${ }^{41}$ My overall contention thus far has been that the difficulties which one finds in the classical and non-classical foundationalisms, as well as

${ }^{41}$ See fn. 38. 
in the contemporary reliabilist theories are all of a piece, and demand a new theoretical slant.

\section{IV}

The large structure of this piece has been such that we assumed that we can learn something about foundationalism by examining some criticisms of reliabilism (and, implicitly, vice versa) and that what we learn about a classical sort of foundationalism might aid us in the naturalization of epistemic justification theory. In a previous section the desideratum that what one prescribes for an epistemic agent should be within the performance repertoire of that agent was alluded to. Until recently, contemporary epistemology was fraught with theoretical views which were, as Kornblith noted in his original piece, ${ }^{42}$ apsychologistic and acontextual. But the advent of the computational model of mind and the work stemming from the acceptance of that model in many disciplines begs us to alter our epistemic views so as to take into account the agent's actual functioning. Some theories of epistemic justification seem implicitly to have been developed in such a way as to make their amelioration by elements of cognitive science possible and even comparatively easy. The naturalization of epistemology calls for us to utilize those portions of epistemic justification theory which come closer to satisfying our original desideratum and to modify them in ways which capture descriptively the flavor of mental functioning.

42 See fn. 25. 


\section{REFERENCES}

Alston, William P., "Some Remarks on Chisholm's Epistemology", in Noûs, vol. 14, pp. 565-586.

Audi, Robert, "Foundationalism, Epistemic Dependence and Defeasibility", in Synthèse, vol. 55, no. 1, pp. 134-135.

Austin, J.L., Sense and Sensibilia, Oxford: Oxford University Press, 1967.

Cornman, James, "Foundational vs. Nonfoundational Theories of Empirical Justification", in Essays on Knowledge and Justification, en George S. Pappas and Marshall Swain (comps.), Ithaca, NY: Cornell University Press, 1978.

Dretske, Fred, "Epistemic Operators", in Journal of Philosophy, LXVII, December 1971.

Duran, Jane, "A Contextualist Modification of Cornman", in Philosophia, vol. 16, nos. 2 \& 3, 1986.

—_, "Descriptive Epistemology", in Metaphilosophy, vol. 15, nos. $3 \& 4$.

-, "Intentionality and Epistemology", in The Monist, vol. 69 , no. 4 .

__, "Reliabilism, Foundationalism and Naturalized Epistemic Justification Theory", in Metaphilosophy, vol. 19, no. 2.

Foley, Richard, "Chisholm and Coherence", in Philosophical Studies, vol. 38, pp. 53-63.

Goldman, Alvin, Epistemology and Cognition, Cambridge, MA: Harvard University Press, 1986.

Heil, John, "Reliability and Epistemic Merit", in Australasian Journal of Philosophy, vol. 62.

Kornblith, Hilary, Naturalizing Epistemology, Cambridge, MA: Bradford of MIT Press, 1985.

Lehrer, Keith, "Why Not Skepticism?", Philosophical Forum, vol. II, no. 3.

Pastin, Mark, "Modest Foundationalism and Self-Warrant", in Pappas and Swain (comps.).

Pylyshyn, Zenon, Computation and Cognition, Cambridge, MA: Bradford of MIT Press, 1985.

Quine, W.V.O., "Two Dogmas of Empiricism", in From a Logical Point of View, Cambridge, MA: Harvard University Press, 1953. 
Suppe, Frederick, The Structure of Scientific Theories, Champaign-Urbana, IL: University of Illinois Press, 1977.

Triplett, Timm, "Chisholm's Foundationalism", in Philosophical Studies, vol. 38, pp. 141-153.

Recibido: 11 de septiembre de 1995 


\section{RESUMEN}

El reciente proyecto de naturalización de la epistemología ha producido gran cantidad de discusiones teóricas, muchas de las cuales (Goldman, Kornblith) se esfuerzan por aludir a la investigación realizada en las ciencias cognoscitivas con el fin de ayudarnos en nuestra teorización epistémica. Utilizando tres vías principales de argumentación, propongo que examinemos un tipo de fundacionismo clásico (el de Chisholm) en tanto que paradigma de una teoría de la justificación epistémica no naturalizada y concluir a partir de tal examen que ya no hay obstáculos para construir una teoría naturalizada de la justificación epistémica que combine de manera verosímil elementos del coherentismo con elementos de las ciencias cognoscitivas. La primera vía de argumentación se centra en la supuesta relación entre fundacionismo y confiabilismo, y nos pide que notemos que los defectos del fundacionismo son similares a los del confiabilismo y giran en torno de la noción de proceso cognoscitivo privilegiado. La segunda vía de argumentación nos pide reconocer que ciertos tipos de teorías de la justificación epistémica son intuitivamente más naturalizadas (las teorías coherentistas), y la tercera vía de argumentación nos propone imaginar una teoría naturalizada de la coherencia cuyo conjunto justificatorio descansa en un modelo descriptivamente exacto del proceso de justificación epistémico y que elimina algunas de las preocupaciones de los teóricos (por ejemplo Cornman) que han criticado al coherentismo. La conclusión general del artículo es que la teoría de la justificación epistémica puede y debería ser naturalizada, y que el examen de una teoría no naturalizada paradigmática nos indica la dirección correcta.

[Traducción: Héctor Islas] 